\title{
Trends in UK regional cancer mortality 1991-2007
}

\author{
Dominic C Marshall ${ }^{\star, 1,4}$, Thomas E Webb ${ }^{1,4}$, Richard A Hall ${ }^{1,4}$, Justin D Salciccioli ${ }^{1}$, Raghib Ali $^{2}$ and \\ Mahiben Maruthappu ${ }^{3}$ \\ ${ }^{1}$ Department of Medicine, Imperial College London, London SW7 2AZ, UK; ${ }^{2}$ Cancer Epidemiology Unit, University of Oxford, \\ Oxford OX3 7LF, UK and ${ }^{3}$ Foundation School, Imperial College London, London UK
}

Background: Until 1990, there was an upward trend in mortality from breast, lung, prostate, and colon cancers in the United Kingdom. With improvements in cancer treatment there has, in general, been a fall in mortality over the last 20 years. We evaluate regional cancer mortality trends in the United Kingdom between 1991 and 2007.

Methods: We analysed mortality trends for breast, lung, prostate, and colon cancers using data obtained from the EUREG cancer database. We have described changes in age-standardised rates (using European standard population) per 100000 for cancer mortality and generated trends in mortality for the 11 regions using Joinpoint regression.

Results: Across all regions in the United Kingdom there was a downward trend in mortality for the four most common cancers in males and females. Overall, deaths from colon cancer decreased most rapidly and deaths from prostate cancer decreased at the slowest rate. Similar downward trends in mortality were observed across all regions of the United Kingdom with the data for lung cancer exhibiting the greatest variation.

Conclusions: Mortality from the four most common cancers decreased across all regions of the United Kingdom; however, the rate of decline varied between cancer type and in some instances by region.

Despite a general downward trend in mortality, cancer remains one of the most common causes of death in the United Kingdom (UK). Of the 200 types of cancer believed to occur in humans, just 4 are responsible for over half of all cases of cancer and a similar proportion of deaths (Jemal et al, 2011); these are colon, breast, lung, and prostate cancers. Although overall trends in UK cancer mortality have been decreasing steadily, variation between regions within the United Kingdom may be apparent, as has been reported in other health-care systems (Naishadham et al, 2011).

Previous studies investigating trends in cancer rates over the last 50 years have identified a peak in incidence in the late 1980s followed by a steady decrease over the past 20 years (Bosetti et al, 2013). However, with the exception of lung cancer in males and lung cancer in females, breast, prostate, and colon cancer incidence has increased (Mistry et al, 2011). Colon cancer incidence in England and Wales increased moderately between 1971 and 1999 while combined male-female mortality fell by $\sim 30 \%$ (Hayne $e t a l$, 2001). Breast cancer incidence has also increased from 79.8/ 100000 in 1984 to $120.3 / 100000$ in 2007 (Mistry et al, 2011). Similarly, prostate cancer incidence more than doubled over the same time period increasing from 40.5/100000 in 1984 to 97.2/ 100000 in 2007 (Mistry et al, 2011). Although the incidence remains higher in men, lung cancer rates have halved over the previous 30 years in men and remained stable in women (Mistry et al, 2011). Although the National Health Service (NHS) is responsible for providing health-care services to the majority of the population, there are regional variations in service provision and no prior reports have addressed whether these lead to regional disparity in cancer mortality across the United Kingdom.

The analysis of cancer mortality trends across regions provides insights into the risk factors for a particular disease and also provides information into the effectiveness of different treatments

\footnotetext{
*Correspondence: DC Marshall; E-mail: dominic.marshall12@imperial.ac.uk

${ }^{4}$ These authors contributed equally to this work.
}

Received 2 August 2015; revised 28 October 2015; accepted 7 November 2015; published online 14 January 2016

(C) 2016 Cancer Research UK. All rights reserved 0007-0920/16 
or diagnostic strategies. In this study, we analysed trends in age-standardised mortality data for breast, colon, lung, and prostate cancers in the United Kingdom between 1991 and 2007. To compare regions of the United Kingdom, data were delineated into 11 regions of data collected by local cancer registries.

\section{MATERIALS AND METHODS}

Study design. We performed an observational, retrospective, population-level study to report regional mortality rates for breast, colon, prostate, and lung cancers. We defined comparator regions as the 11 local cancer registries in the United Kingdom. The local registries cover eight regions of England plus Scotland, Wales, and Northern Ireland. There is variation between the regions on population sizes and demographics, structure of the registry, and method of data collection, which are outlined in Curado et al (2007). We compared mortality rates and trends in mortality rates across these regions.

Data source. Cancer mortality data were collected by populationbased cancer registries for UK regions (Steliarova-Foucher et al, 2013). Cancer diagnoses were recorded according to the International Classification of Disease (ICD) at the time of death. During the calendar period for this investigation two different revisions of the ICD were used, the 9th revision was used across the United Kingdom until 2001 when the 10th revision was implemented. Mortality data for cancers of interest are available publically through the World Health Organisation and can be abstracted from the EUREG database (http://eco.iarc.fr/eureg/; accessed 09/ 2014) developed by the International Agency for Research on Cancer (IARC) in partnership with the European Network of Cancer Registries. IARC is responsible for data management and maintains data quality through their Check and Conversion program, which includes routine screening with pre-defined algorithms for validity and consistency (Ferlay et al, 2005).

In the United Kingdom, all death certificates in which cancer is mentioned are automatically sent to relevant cancer registry which between them cover the entire United Kingdom; therefore, cancer data are considered as almost complete for the United Kingdom (Peto et al, 2000a). Cancer mortality in this data set includes cancer patients who were not registered with a cancer registry before their death. Regional cancer registries all collect data to a national standard that comply with the IARC guidelines, they are then submitted to the Office of National Statistics (ONS), General Registry for Scotland, or General Registry for Northern Ireland. The ONS carry out further validation of the submissions (Office for National Statistics, 2010), including cause of death, site of cancer identification, and comparability of cancer sites. If the ONS finds a data set is not valid, it is returned to the registry for resolution (Office for National Statistics, 2009). This provides a level of consistency between regions, and remove concerns that are typically present when comparing cancer registry data between countries (Allemani et al, 2015).

Data handling. The data for the current study were extracted from the EUREG database. EUREG collected the data via a protocol outlined by Steliarova-Foucher et al (2015). Abstracted regional data from the IARC database were collated into Microsoft Excel. Mortality data were averaged for the period 2003-2007 to allow comparison of the most recent available mortality rates by regions as previously reported in the literature (Bosetti et al, 2013). We used single-year mortality data to examine trends in agestandardised cancer rates across regions. Average mortality rates (period 2003-2007) per 100000 person-years standardised to the European standard population are presented for males and females for breast, lung, colon, and prostate cancer by region of the United Kingdom. Subgroups of age were extracted directly from the database, and are calculated by dividing the number of new cancer deaths observed in a given age range during the stated time period by the corresponding number of person-years in the population at risk in the same age range and time period and these data are reported in the Supplementary material. Average rates for period 2003-2007 were extracted from the database, and are computed as the mean value for the years 2003, 2004, 2005, 2006, and 2007.

Data analysis. Statistical trends were assessed for the period 1991-2007 using Joinpoint software (Version 4.1.1.1) provided by the United States National Cancer Institute Surveillance Research Program (http://surveillance.cancer.gov/joinpoint/). Joinpoint regression analysis assesses changes in linear slope for mortality trends over time (Kim et al, 2000) as described previously (Bosetti et al, 2013). To characterise mortality trends, Joinpoint regression generates joined linear segments on a logarithmic scale. A series of permutation tests are performed initially with no Joinpoints and tests for changes in the model with sequential addition of points where there is a significant change in the slope of the line (Kim et al, 2000). From each of the models, the Joinpoint software produces summary statistics on the annual percentage change (APC) for each line segment.

\section{RESULTS}

Standardised average mortality rates (period 2003-2007) are shown in Table 1. On average for the period 2003-2007, lung cancer was found to be the greatest cause of mortality (40.3/ $100000)$, followed by breast cancer $(28.1 / 100000)$ (females only) then prostate cancer (25.7/100000) then colon cancer (11.5/ $100000)$. No single region consistently outperformed the rest on overall changes in cancer mortality. On average, over the 2003 2007 period the region with the highest mortality for breast cancer in females was Oxford (29.9/100000) and the region with the lowest was North and Yorkshire (26.9/100 000). Northern Ireland had the highest mortality rate for colon cancer $(14.0 / 100000)$ and the Thames region has the lowest (10.8/100 000). Lung cancer mortality was highest in Scotland (55.9/100 000/year) and lowest in the South West region (31.3/100 000). There was less variation in prostate cancer mortality, with the highest rates in Oxford (26.5/ $100000)$ and the lowest in North West England (24.7/100 000) (Table 1).

Overview of trends. Between 1991 and 2007, age-standardised mortality rates declined for breast, lung, colon, and prostate cancers in the United Kingdom (Figure 1). For all four cancer types across all regions, there was a decrease in age-standardised mortality rates for males and females. Further subgroups of age, $20-39,40-59,60-79$, and $80+$, by cancer and region are included as Supplementary materials. Table 2 provides results of the Joinpoint analysis, each joinpoint representing a change in the trend for the mortality rates in each region. This is presented as APC for the corresponding period of time. Further subgroups of age for all regions and cancer types are available as Supplementary materials.

\section{Regional trends by cancer type}

Colon. Across all regions, colon cancer decreased between 1991 and 2007 (Figure 2). For the period 2003-2007, Thames and East England had the lowest rates of colon cancer mortality (10.8/ 100000 and 10.9/100000, respectively) whereas Scotland and Wales had the highest (12.3/100 000 and 13.2/100 000, respectively) (Table 1). All regions demonstrated a significant downward trend over the period from 1991 to 2007 (all $P<0.05$ ) (Table 2). Regional estimated percentage annual change (EPAC) in mortality ranged from $-2.96 \% /$ year in Trent to $-2.29 \% /$ year in Oxford. 
Table 1. Average age-standardised UK regional mortality rates for colon, lung, breast, and prostate cancers (2003-2007)

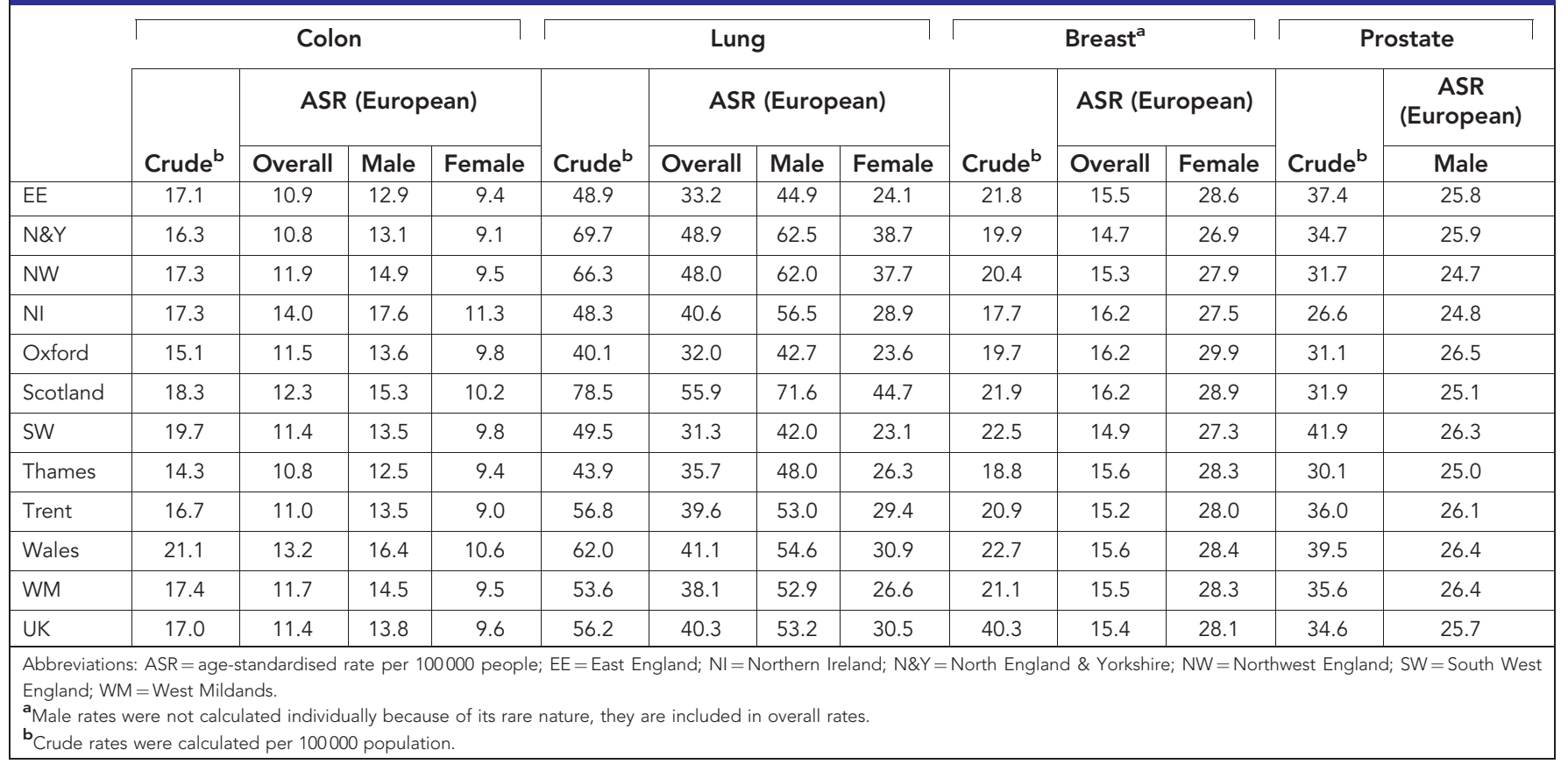
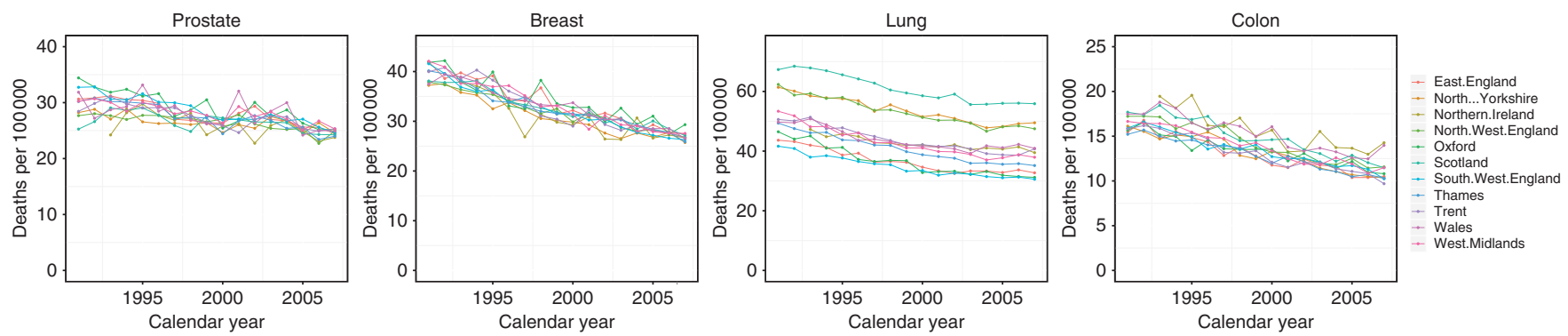

Figure 1. Cancer mortality per 100000 person-years age standardised to European standard population for colon, lung, breast, and prostate cancers across 11 regions of the United Kingdom, 1991-2007.

There were no significant trend changes in colon cancer mortality in any of the regions. The proportion of women dying from colon cancer remained consistent over the study period.

Lung. All regions demonstrated a reduction in lung cancer mortality between 1991 and 2007 (Figure 3). Lung cancer exhibited the greatest regional variance. For the 2003-2007 period, the South-West England and Oxford regions had the lowest rates $(31.3 / 100000$ and 32.0/100000, respectively) and Scotland and North and Yorkshire had the highest (55.9/100000 and 48.9/ 100000 , respectively) (Table 1). Favourable trends were observed in all regions throughout the 1990s (except Wales); ranging from $-3.48 \%$ /year in Oxford to $-1.73 \%$ /year in North and Yorkshire (Table 2). Later in the study period, beginning between 2000 and 2003, all regions experienced smaller year on year mortality reductions (Table 2); Trent and North and Yorkshire demonstrated a small increasing trend in 2005-2007, however, this was not statistically significant.

Across all regions, the proportion of women dying from lung cancer increased between 1991 and 2007 (Figure 3) due to a decrease in male mortality rates.

Breast. Breast cancer mortality decreased in all regions (Figure 4) and demonstrated minor variation between regions ranging from the lowest rates for the 2003-2007 period in the North and Yorkshire and SW England regions (14.7/100000 and 14.9/
100000 , respectively) and the highest in Oxford, Northern Ireland, and Scotland (all 16.2/100 000) (Table 1). All regions, excluding Trent and Wales, showed one continuous trend between 1991 and 2007 with a favourable change in mortality ranging from $-3.64 \%$ / year in Thames to $-2.13 \% / y e a r$ in Scotland (Table 2). The Trent region had three separate trends with the highest year on year decrease between 2003 and 2007 (-3.50\%/year) (Table 2). Wales also had three separate trends ranging from $-1.61 \% /$ year for the 1998-2007 period to $-6.90 \% / y e a r$ for the $1995-1998$ period, although the latter was non-significant.

Prostate. Regional prostate cancer mortality for the 2003-2007 period ranged from the lowest in rate in North West England and Northern Ireland (24.7/100 000 and $24.8 / 100000$, respectively) to the highest in Oxford and Wales (26.5/100 000 and 26.4/100 000, respectively) (Table 1). All regions demonstrated a reduction in mortality between 1991 and 2007 (Figure 5). All regions, excluding Scotland and East England, also demonstrated one significant downward trend during the period 1991-2007 ranging from $-0.67 \% / y e a r$ in North and Yorkshire to $-1.68 \% / y e a r$ in Oxford. East England demonstrated two significant downward trends interspaced with a non-significant rise in mortality (Table 2). Trends for Scotland show an initial non-significant increase in mortality from 1991 to 1993 before a favourable trend of $-1.10 \% /$ year for the 1993-2007 period. 
Table 2. Joinpoint regression analysis of trends in breast, lung, colon, and prostate cancers mortality by region (1991-2007)

\begin{tabular}{|c|c|c|c|c|c|c|c|c|}
\hline & \multicolumn{2}{|c|}{ Trend 1} & \multicolumn{2}{|c|}{ Trend 2} & \multicolumn{2}{|c|}{ Trend 3} & \multicolumn{2}{|c|}{ Trend 4} \\
\hline \multicolumn{9}{|l|}{ Colon } \\
\hline$N \& Y$ & 1991-2007 & $-2.85^{\star}$ & & & & & & \\
\hline NW & 1991-2007 & $-2.88^{\star}$ & & & & & & \\
\hline$N l^{a}$ & 1993-2007 & $-2.59^{\star}$ & & & & & & \\
\hline Oxford & 1991-2007 & $-2.29 *$ & & & & & & \\
\hline Thames & $1991-2007$ & $-2.66^{*}$ & & & & & & \\
\hline Trent & 1991-2007 & $-2.96^{\star}$ & & & & & & \\
\hline Wales & 1991-2007 & $-2.36^{\star}$ & & & & & & \\
\hline WM & 1991-2007 & $-2.70^{\star}$ & & & & & & \\
\hline \multicolumn{9}{|l|}{ Lung } \\
\hline $\mathrm{EE}$ & 1991-2002 & $-2.62^{\star}$ & $2002-2007$ & 0.22 & \multirow{6}{*}{ 1996-2003 } & \multirow{6}{*}{$-1.32^{\star}$} & \multirow{6}{*}{ 2003-2007 } & \multirow{6}{*}{1.01} \\
\hline & $1991-2001$ & $-2.38^{\star}$ & $2001-2007$ & $-0.88^{\star}$ & & & & \\
\hline Thames & $1991-2003$ & $-2.49^{*}$ & 2003-2007 & -0.68 & & & & \\
\hline Trent & $1991-2005$ & $-2.03^{*}$ & $2005-2007$ & 2.55 & & & & \\
\hline Wales & $1991-1993$ & 1.46 & $1993-1996$ & $-4.60^{\star}$ & & & & \\
\hline WM & 1991-1999 & $-3.15^{\star}$ & 1999-2007 & -1.11 & & & & \\
\hline \multicolumn{9}{|l|}{ Breast } \\
\hline $\mathrm{EE}$ & 1991-2007 & $-2.59^{*}$ & \multirow{7}{*}{$\begin{array}{l}1997-2003 \\
1995-1998\end{array}$} & \multirow{7}{*}{$\begin{array}{l}-1.17^{\star} \\
-6.9\end{array}$} & \multirow{7}{*}{$\begin{array}{l}2003-2007 \\
1998-2007\end{array}$} & \multirow{7}{*}{$\begin{array}{l}-3.50^{\star} \\
-1.61^{\star}\end{array}$} & & \\
\hline$N \& Y$ & 1991-2007 & $-2.34^{\star}$ & & & & & & \\
\hline NW & $1991-2007$ & $-2.15^{\star}$ & & & & & & \\
\hline $\mathrm{Nl}^{\mathrm{a}}$ & 1993-2007 & $-2.26^{*}$ & & & & & & \\
\hline Oxford & 1991-2007 & $-2.27^{\star}$ & & & & & & \\
\hline Scotland & $1991-2007$ & $-2.13^{*}$ & & & & & & \\
\hline & $1991-2007$ & $-2.70^{*}$ & & & & & & \\
\hline $\mathrm{Nl}^{\mathrm{a}}$ & 1993-2007 & $-1.00^{\star}$ & \multirow{8}{*}{ 1995-1999 } & \multirow{8}{*}{$-4.04^{\star}$} & \multirow{8}{*}{ 1999-2002 } & \multirow{8}{*}{3.51} & & \\
\hline Oxford & $1991-2007$ & $-1.68^{\star}$ & & & & & & \\
\hline Scotland & 1991-1993 & 6.87 & & & & & & \\
\hline & $1991-2007$ & $-1.59^{*}$ & & & & & & \\
\hline Thames & $1991-2007$ & $-1.55^{\star}$ & & & & & & \\
\hline Trent & $1991-2007$ & $-1.14^{\star}$ & & & & & & \\
\hline Wales & $1991-2007$ & $-1.02^{\star}$ & & & & & & \\
\hline WM & 1991-2007 & $-1.02^{\star}$ & & & & & & \\
\hline
\end{tabular}

\section{DISCUSSION}

Across all regions, rates of mortality from all four cancers were lower in 2007 than in 1991. There were no peaks or troughs in mortality that affected all of the study sites. Overall, deaths from colon cancer decreased most rapidly. Rates of death from prostate cancer fell the least over the study period. Lung cancer exhibited the greatest regional variation in mortality rates, mortality trends, and also caused the greatest proportion of deaths. Breast, prostate, and colon cancers demonstrated similar small variations in regional mortality with most regions exhibiting one consistent downward trend.

Across all regions of the United Kingdom, consistent reductions in colon cancer mortality have been identified despite increases in incidence. As the population is exposed to an increase in many lifestyle and dietary risk factors such as alcohol, obesity, and diabetes (Huxley et al, 2009) it is encouraging that a downward trend is exhibited across all regions. Beyond our study period, this trend seems to have continued, possibly due to the introduction of the NHS Bowel Screening Programme in 2006 (Siegel et al, 2013). Faecal occult blood screening for colon cancer could potentially reduce mortality by up to $16 \%$ in those offered the test (Bernie et al, 1998; Logan et al, 2011). Further, we identified minimal regional variation in colon cancer mortality, suggesting that improvements in colon cancer treatment have been implemented successfully across the United Kingdom. The aim of the UK's bowel screening programme is purportedly to improve upon these regional trends in colon cancer survival; however, the true effect of this programme has yet to be fully described. 

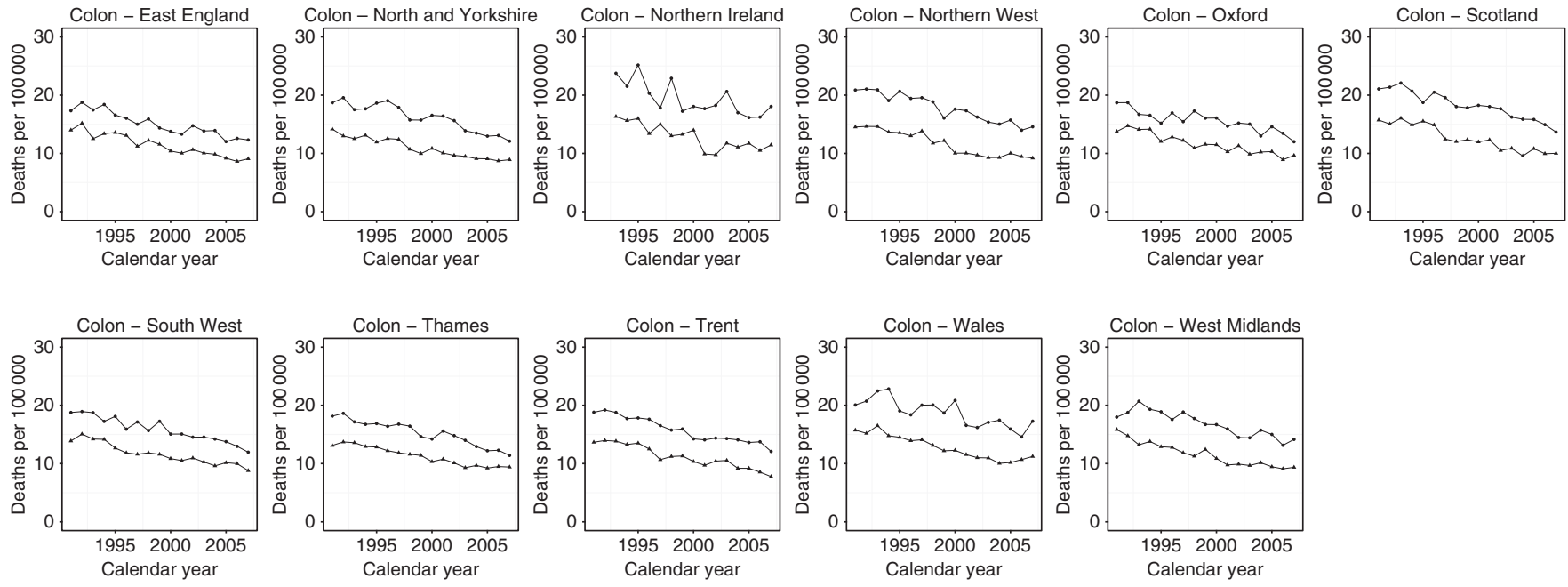

Figure 2. Trends in age-standardised (European) mortality rates from colon cancer across 11 regions of the United Kingdom, 1991-2007. Circles represent men, all ages; triangles represent women, all ages.
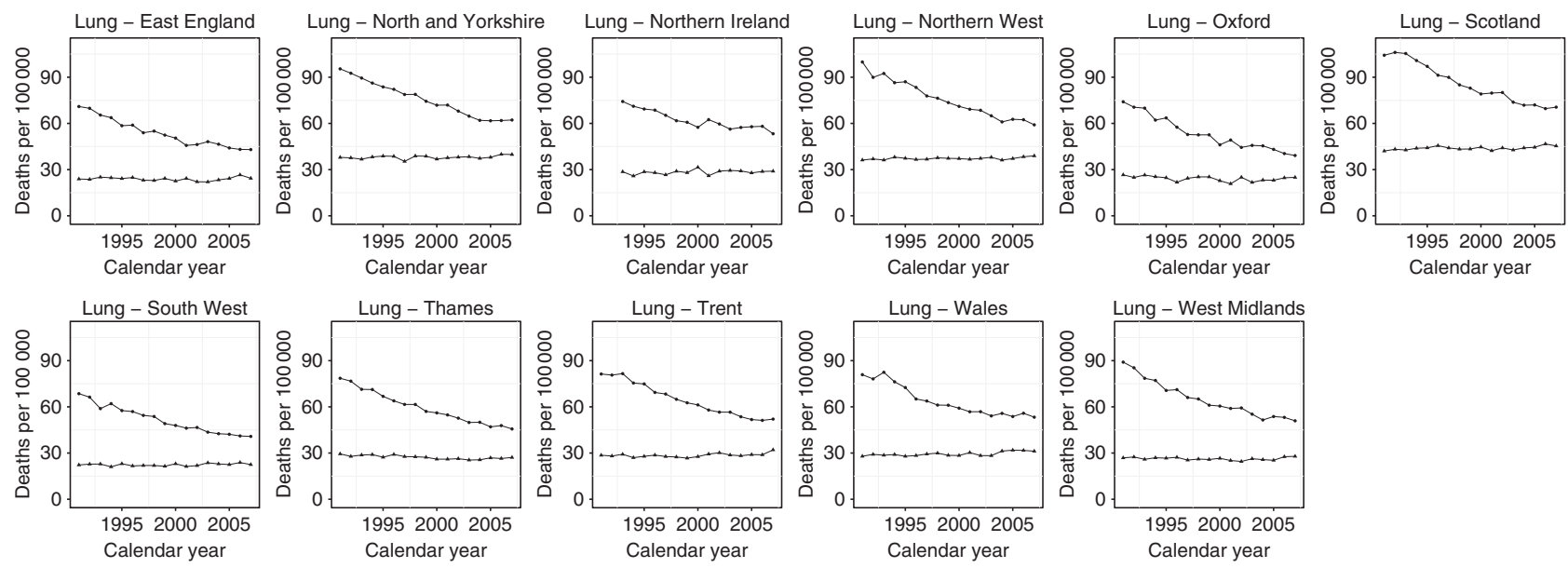

Figure 3. Trends in age-standardised (European) mortality rates from lung cancer across 11 regions of the United Kingdom, $1991-2007$.

Circles represent men, all ages; triangles represent women, all ages.
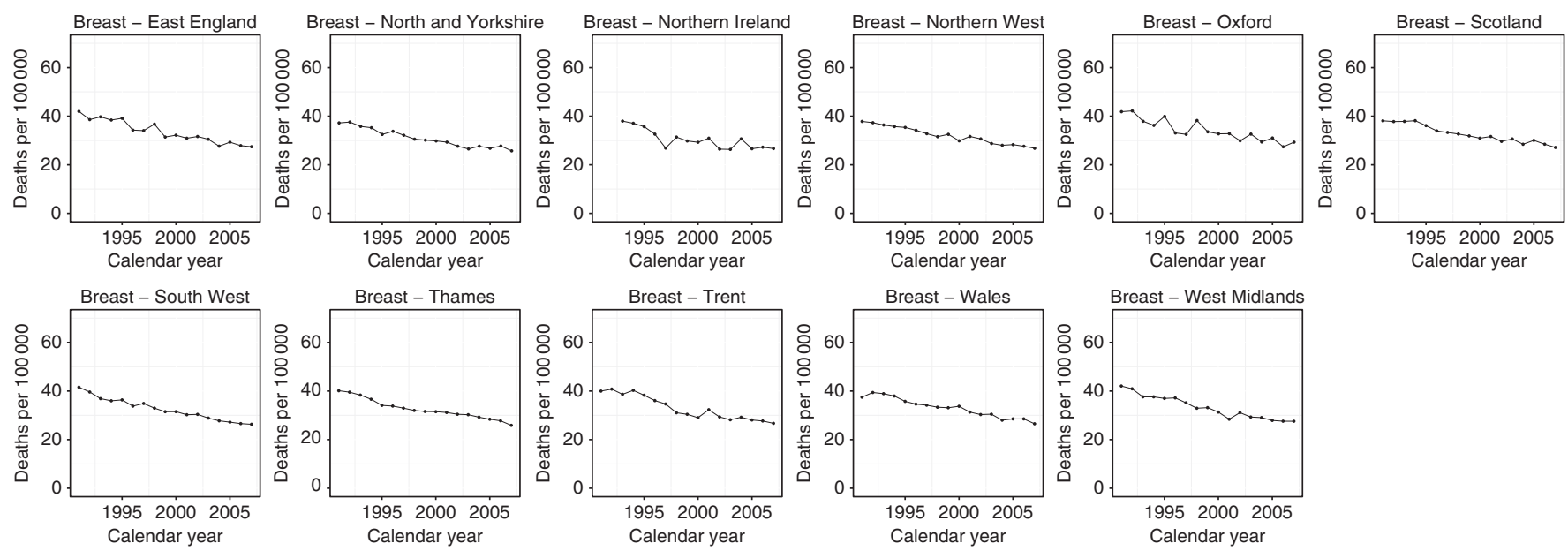

Figure 4. Trends in age-standardised (European) mortality rates from breast cancer across 11 regions of the United Kingdom, $1991-2007$. Circles represents women, all ages.

Overall, deaths from lung cancer have greatly reduced over the study period but there is a high degree of regional variation. The geographical inequality observed in the current study may be explained by the different rates of smoking across the United
Kingdom, with rates of lung cancer highly correlated well with areas with high smoking rates (Twigg et al, 2004). In the 1990s, across all regions, there was a clear downward trend in lung cancer mortality. In the early 2000s, overall mortality began to plateau in 

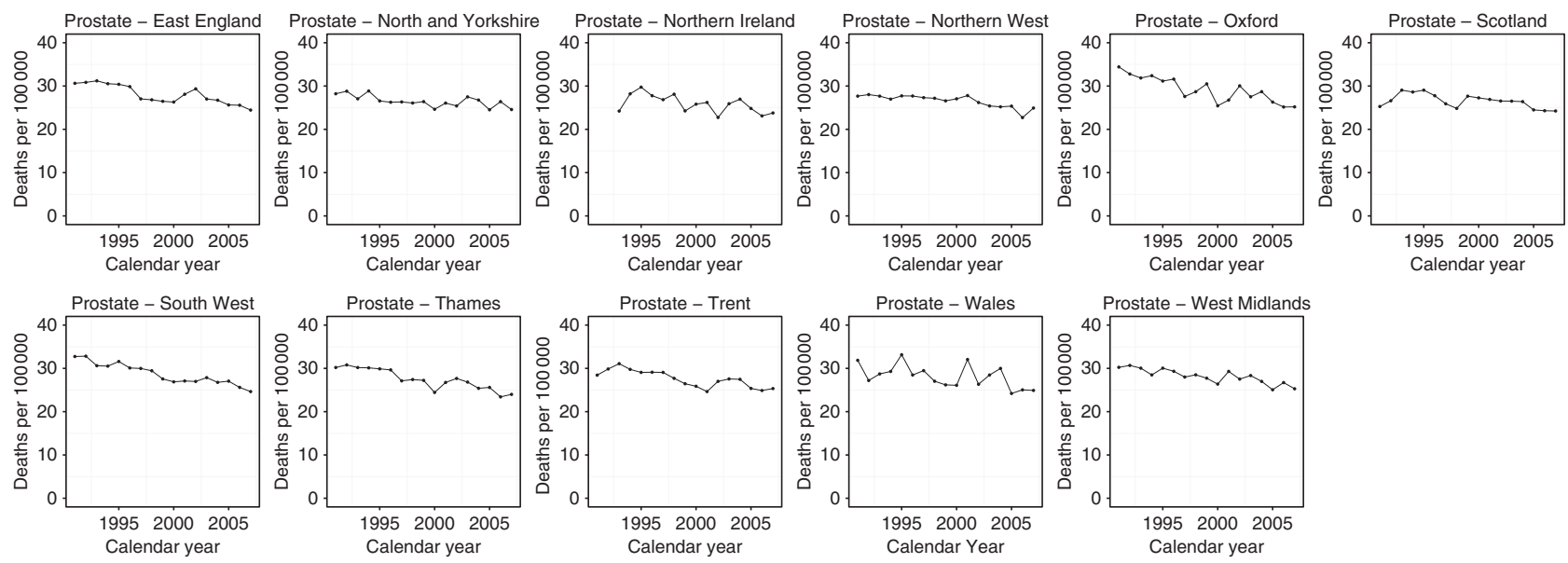

Figure 5. Trends in age-standardised (European) mortality rates from prostate cancer across 11 regions of the United Kingdom, $1991-2007$.

Circles represent men, all ages.

many regions and rise in others, specifically Trent and North and Yorkshire, notably some of the trends were non-significant. The weakening trends are in contrast to colon, breast, and prostate cancers, all of which demonstrate continuous, significant, improvements in mortality. The reason for this is not clear, and a combination of the rise in female smokers outweighing improvement in treatment, increasing younger deaths, and limited new effective therapies may all be contributing factors (Malvezzi et al, 2013).

The observation that the proportion of deaths from lung cancer among women increased with time is possibly attributable to the later peak in the prevalence of female smoking compared with males (Peto et al, 2000b). The effect of the decline in smoking in men is already reflected in the mortality data, but has yet to happen in the data for women (Peto et al, 2000b).

There was an overall downward trend in mortality from breast cancer across all regions with small variation in rates between regions, again despite increased incidence. The introduction of hormonal treatments and the increasing use of cytotoxic agents is believed to have contributed to this (Peto et al, 2000a). Specifically, the increasingly widespread use of Tamoxifen (Autier et al, 2010). Furthermore, the introduction of breast cancer screening in 1988 and two-view mammography in 2003 may have aided early diagnosis and reductions in mortality (Independent UK Panel on Breast Cancer Screening, 2012). National falls in breast cancer mortality have continued until 2012 (Cancer Research UK), but regional data were not available for the current investigation.

Recent data from Cancer Research UK found breast cancer to be increasingly common in women under 50 (Cancer Research UK). This, in combination with our findings, may support decisions to investigate the feasibility of extending national breast screening to include patients aged 47-49 (Moser et al, 2011). However, given that breast cancer is rarer in younger women, the rate of overdiagnosis is likely to increase if this demographic was to be included. The ratio currently stands at one breast cancer death prevented for every three cases of overdiagnosis (Marmot et al, 2013), this would likely improve breast cancer survival statistics but have a small effect on mortality. The surgical and medical treatments for breast cancer are invasive and often highly unpleasant. Overdiagnosis exposes women to these treatments who have tumours that may never have caused morbidity during their lifetime (Marmot et al, 2013). The infrequency of breast cancer in younger women also means an increase in financial cost per life saved as more women will have to be screened per cancer diagnosis. In extending the screening ages, the myriad of minor disadvantages must not be overlooked such as the inconvenience of having to attend the appointment and the discomfort and occasionally pain caused by the mammogram itself (Marmot et al, 2013).

Regions with the lowest breast cancer mortality experienced a diminution in the rate at which mortality declined. This may mean that more effective practices such as advances in surgery and chemotherapeutics are being adopted across the study sites (Etzioni et al, 2013).

Prostate cancer rates have shown the smallest decrease in mortality rates compared with breast, lung, and colon. However, in 1991 there was a greater degree of regional variation, which reduces as the data converges by 2007 . These trends may be a result of the different regions all adopting advances in diagnosis by PSA testing and treatment by radical prostatectomy as well as improvements in radiotherapy and adjuvant chemotherapy (Hanchanale and McCabe, 2010; Etzioni et al, 2013).

Overall, these trends are consistent with those observed by others, demonstrating a constant decline in deaths from cancers since the late 1980s (Siegel et al, 2013). This study corroborates existing evidence showing that deaths from colon cancer have been falling rapidly in recent decades (Siegel et al, 2013). Decreases in cancer-related mortality may be largely due to improvements in diagnosis, meaning that cancers were identified earlier when treatment had a better prognosis (Siegel et al, 2013). Access to a healthier diet enabled by increasing affluence may have also contributed to the decline in colon cancer mortality (Bosetti et al, 2011). Minor variation in the mortality rates between the more affluent East England and Thames compared with Northern Ireland, Wales, and Scotland. On average, all regions in the current study demonstrated a decreasing trend in mortality, with minor variation between regions which suggests that unified nationwide falls in mortality are possible irrespective of variation in regional demographics.

Mortality rates, and particularly changing trends in mortality rates, are a crude measure of the effectiveness of health-care policies. These policies include screening programmes, lifestyle campaigns, awareness campaigns, and availability of treatments. Monitoring these trends will permit ongoing variations to be identified, and in turn, minimised.

Strengths and limitations. To the best of our knowledge, this is the first investigation to compare regional variations in cancerrelated mortality trends within the United Kingdom. Previous investigations have highlighted such trends in other health-care systems (Naishadham et al, 2011). Although previous reports have focused on mortality statistics relating to a single type of cancer, we have included in this investigation the four most common cancers in the United Kingdom. This approach allows for broad exposure 
and interpretation of overall performance in cancer mortality statistics across the United Kingdom.

A number of limitations should also be considered when interpreting the results of this investigation. First, this is an observational study subject to limitations of any observational study with surveillance data and we are unable to account for specific variations within regions. Second, although more recent data are available for the United Kingdom, regional mortality data were only available to 2007 and we were unable to assess regional changes in mortality trends until the present. However, data were available dating back to the early 1990s and we were able to assess trends over a 17-year period. Whether these trends have persisted for the years since 2007 should be the focus of future investigations. Further, mortality data for Northern Ireland for 1991 and 1992 were also unavailable. This may mean that the relative mortality in Northern Ireland may be slightly underrepresented since the highest rates of death tended to be in the earlier years of the study. Third, we did not include data for deaths from breast cancer in men. Although this variant of the disease is admittedly very rare, it is often overlooked altogether (Gethins, 2012).

The current study did not independently validate the individual regional data; however, previous studies have reported that the quality of UK cancer registry data to be high (Allemani et al, 2015). Mortality data are virtually complete as a death certification is a legal obligation; however, there are known imperfections (Devis and Rooney, 1999). Ascertaining the cause of death can be difficult, especially in elderly cancer patients who often may have secondary conditions imposed upon an underlying cancer, leading to inaccuracies in certification (Fall et al, 2008).

The authors find it reasonable to assume that while small variations almost certainly exist between regions, any significant variations are unlikely to be accountable to these factors alone. Furthermore, the ONS and general registry offices undergo a vigorous process to ensure national mortality data are accurate and valid (Office for National Statistics, 2006).

Mortality is generally accepted as a valuable measure for aggressive diseases, such as breast, lung, prostate, and colon cancers (Alderson, 1976). However, the analysis of mortality data in isolation has drawbacks that must be acknowledged. It is important to note that the geographical differences in mortality are observed in the context of differing rates of incidence. Existing regional variation in the prevalence of cancers may be due to different demographics, including socio-economic status, smoking, and age variation (Mohan, 2014). The disparity in incidence may not be accurately represented by mortality rates (Freedman and Rubin, 1979).

\section{CONCLUSIONS}

Mortality from the four most common cancers decreased across all regions of the United Kingdom from 1991 to 2007. The rate of decline varied between cancer type, age, and in some instances by region. Although the rate of decline in these cancers is generally consistent across regions, disparities in the incidence and mortality of lung, breast, colon, and prostate cancers persist. With the introduction of a greater range of health-care providers, it is important to remain vigilant for any increases in regional variation in mortality rates.

\section{REFERENCES}

Alderson M (1976) An Introduction to Epidemiology. MacMillan Press Ltd.: London, $\mathrm{p} 21$.
Allemani C, Weir HK, Carreira H, Harewood R, Spika D, Wang X-S, Bannon F, Ahn JV, Johnson CJ, Bonaventure A (2015) Global surveillance of cancer survival 1995-2009: analysis of individual data for 25676887 patients from 279 population-based registries in 67 countries (CONCORD-2). Lancet 385: 977-1010.

Autier P, Boniol M, LaVecchia C, Vatten L, Gavin A, Héry C, Heanue M (2010) Disparities in breast cancer mortality trends between 30 European countries: retrospective trend analysis of WHO mortality database. BMJ 341: c3620.

Bernie T, Les I, Paul G, Jan K, David W, Chris S (1998) A systematic review of the effects of screening for colorectal cancer using the faecal occult blood test, hemoccult. BMJ 317: 559-565.

Bosetti C, Bertuccio P, Malvezzi M, Levi F, Chatenoud L, Negri E, La Vecchia C (2013) Cancer mortality in Europe, 2005-2009, and an overview of trends since 1980. Ann Oncol 24: 2657-2671.

Bosetti C, Levi F, Rosato V, Bertuccio P, Lucchini F, Negri E, La Vecchia C (2011) Recent trends in colorectal cancer mortality in Europe. Int J cancer 129: 180-191.

Cancer Research UK. Cancer Research UK. Available from http://www.cancerresearchuk.org/cancer-info/cancerstats/.

Curado MP, Edwards BK, Shin HR et al. eds. Cancer incidence in five continents. Vol. IX (9). ARC Press: Lyon, France, 2007 (IARC scientific publications no. 160).

Devis T, Rooney C (1999) Death Certification and the Epidemiologist. Health Statistics Quarterly, pp 21-34.

Etzioni R, Durand-Zaleski I, Lansdorp-Vogelaar I (2013) Evaluation of new technologies for cancer control based on population trends in disease incidence and mortality. J Natl Cancer Inst Monogr 2013: 117-123.

Fall K, Strömberg F, Rosell J, Andrèn O, Varenhorst E (2008) Reliability of death certificates in prostate cancer patients. Scand J Urol Nephrol 42(4): 352-357.

Ferlay J, Burkhard C, Whelan S, Parkin DM (2005) Check and Conversion Programs for Cancer Registries (IARC/IACR Tools for Cancer Registries). International Agency for Research on Cancer: Lyon.

Freedman LS, Rubin SG (1979) Limitations of mortality data as a guide to comparative lung cancer incidence within an urban area. Public Health 93 : 111-116.

Gethins M (2012) Breast cancer in men. J Natl Cancer Inst 104: 436-438.

Hanchanale VS, McCabe JE (2010) Radical prostatectomy practice in England. Urol J 7: 243-248.

Hayne D, Brown RSD, McCormack M, Quinn MJ, Payne HA, Babb P (2001) Current trends in colorectal cancer: site, incidence, mortality and survival in England and Wales. Clin Oncol 13: 448-452.

Huxley RR, Ansary-Moghaddam A, Clifton P, Czernichow S, Parr CL, Woodward M (2009) The impact of dietary and lifestyle risk factors on risk of colorectal cancer: a quantitative overview of the epidemiological evidence. Int J Cancer 125: 171-180.

Jemal A, Bray F, Center MM, Ferlay J, Ward E, Forman D (2011) Global cancer statistics. CA Cancer J Clin 61: 69-90.

Kim H, Fay MP, Feuer EJ, Midthune DN (2000) Permutation tests for joinpoint regression with applications to cancer rates. Stat Med 19: 335-351.

Logan RFA, Patnick J, Nickerson C, Coleman L, Rutter MD, von Wagner C (2011) Outcomes of the Bowel Cancer Screening Programme (BCSP) in England after the first 1 million tests. Gut 61: 1439-1446.

Malvezzi M, Bertuccio P, Levi F, La Vecchia C, Negri E (2013) European cancer mortality predictions for the year 2013. Ann Oncol 24: 792-800.

Marmot MG, Altman DG, Cameron DA, Dewar JA, Thompson SG, Wilcox M. Independent UK Panel on Breast Cancer Screening (2013) The benefits and harms of breast cancer screening: an independent review: a report jointly commissioned by Cancer Research UK and the Department of Health (England) October 2012. Br J Cancer 108: 2205-2240.

Mistry M, Parkin DM, Ahmad AS, Sasieni P (2011) Cancer incidence in the United Kingdom: projections to the year 2030. Br J Cancer 105: 1795-1803.

Mohan J (2014) A United Kingdom?: Economic, Social and Political Geographies. Routledge.

Moser K, Sellars S, Wheaton M, Cooke J, Duncan A, Maxwell A, Michell M, Wilson M, Beral V, Peto R (2011) Extending the age range for breast screening in England: pilot study to assess the feasibility and acceptability of randomization. J Med Screen 18: 96-102. 
Naishadham D, Lansdorp-Vogelaar I, Siegel R, Cokkinides V, Jemal A (2011) State disparities in colorectal cancer mortality patterns in the United States. Cancer Epidemiol Biomarkers Prev 20: 1296-1302.

Office for National Statistics (2006) Mortality Statistics cause: Review of the Registrar General on deaths by cause, sex and age in England and Wales. Office for National Statistics: National Statistics London.

Office for National Statistics (2010) Cancer Statistic Registrations: Registration of Cancer Diagnosed in 2007. Office for National Statistics: National Statistics London.

Peto R, Boreham J, Clarke M, Davies C, Beral V (2000a) UK and USA breast cancer deaths down 25\% in year 2000 at ages 20-69 years. Lancet 355: 1822.

Peto R, Darby S, Deo H, Silcocks P, Whitley E, Doll R (2000b) Smoking, smoking cessation, and lung cancer in the UK since 1950: combination of national statistics with two case-control studies. BMJ 321: 323-329.

Independent UK Panel on Breast Cancer Screening (2012) The benefits and harms of breast cancer screening: an independent review. Lancet 380: 1778.

Siegel R, Naishadham D, Jemal A (2013) Cancer statistics, 2013. CA Cancer J Clin 63: 11-30.
Steliarova-Foucher E, O'callaghan M, Ferlay J, Masuyer E, Forman D, Comber H, Bray F (2013) European Cancer Observatory: Cancer Incidence, Mortality, Prevalence and Survival in Europe. Version 1.0 (September 2012). European Network of Cancer Registries, International Agency for Research on Cancer. Available from http://eco.iarc.fr (accessed September 2014) 5: 13.

Steliarova-Foucher E, O'Callaghan M, Ferlay J, Masuyer E, Rosso S, Forman D, Bray F, Comber H (2015) The European cancer observatory: a new data resource. Eur J Cancer 51: 1131-1143.

Twigg L, Moon G, Walker S (2004) The Smoking Epidemic in England. Health Development Agency: London.

This work is published under the standard license to publish agreement. After 12 months the work will become freely available and the license terms will switch to a Creative Commons AttributionNonCommercial-Share Alike 4.0 Unported License.

Supplementary Information accompanies this paper on British Journal of Cancer website (http://www.nature.com/bjc) 